\title{
ON THE FUNCTIONAL INDEPENDENCE OF EXPLICATURES AND IMPLICATURES
}

\author{
THORSTEIN FRETHEIM \\ Norwegian University of Science and Technology
}

\section{A B S T RAC T}

Robyn Carston has proposed that, within Relevance Theory the proposition expressed by an utterance $U$ (its explicature) must play a communicative role that is independent of the role played by any implicature of $U$. Thus no implicature can entail the explicature of $U$, and whenever it looks as if that sort of situation obtains, the presumed implicature should be redefined as the explicature. This paper shows that the assumption that an explicature may not be entailed by an implicature cannot be maintained, but the fact that explicatures and implicatures are not always functionally independent of one another is argued not to be a problem for Relevance Theory.

[1] PRAGMATIC PROCESSES AT THE EXPLICIT AND THE IMPLICIT LEVEL OF COMMUNICATION

There is a general agreement that context and context-sensitive pragmatic processes contribute to the truth conditions of explicitly communicated propositions, but opinions diverge as soon as one starts discussing the extent to which pragmatically derived information should be allowed to intrude into the proposition expressed by an utterance. Adherents of relevance theory (Sperber and Wilson 1986, 1995; Carston 2002) claim that relevance-driven pragmatic inference plays just as important a role in the recovery of the proposition expressed as in the derivation of implicatures, and that the set of truth conditions encoded by a given sentence hardly ever exhausts the set of truth conditions for the proposition that a speaker communicates. Carston says,

If all pragmatically derived elements are treated as implicatures we are left with no candidate for what is said, or the explicit utterance content, other than the logical form of the linguistic expression used, which is standardly subpropositional. But we do not communicate logical forms (though we do communicate via logical forms), and 
we do not retain logical forms in memory; we communicate and remember assumptions or thoughts or opinions, which are fully propositional. So a distinction has to be made between pragmatic inference that contributes to the recovery of the explicitly communicated content and pragmatic inference that eventuates in implicated assumptions. (Carston 2002, 107)

The view expressed in the final sentence of this quotation is expressed even more strongly, and with some added implications, by Recanati $(1989,1993,2004)$, because Recanati makes a distinction between 'primary pragmatic processes', which are pre-propositional and outside the conscious awareness of the interpreter, and 'secondary pragmatic processes', which are said to be post-propositional, and which the interpreter is consciously aware of. The former are local processes that contribute to the hearer's understanding of what is said and are not considered to be inferences in the strict sense; the latter are believed to be true inferences of a global sort. What Recanati labels the Availability Principle is based on the assumption that two qualitatively different types of pragmatic process - primary and secondary - are involved in utterance interpretation. Processing that is required for the determination of the truth conditions of the proposition expressed ('what is said') happens at a sub-conscious level. The output of such processes is consciously available but the processes themselves are not. True inferential processes on the other hand are consciously available and are the ones involved in the derivation of conversational implicatures, at least the particularized ones (PCI's) whose existence depends on inferences that are not of a default sort.

Recanati's position on the difference between two kinds of pragmatic process is generally rejected by leading relevance theorists, who hold that all pragmatic processes are inferential processes of an unreflective nature, and that the processing of explicatures and implicatures happens in parallel, so that the latter kind of inferential process does not depend on the hearer's mental representation of a pragmatically fully developed proposition, an explicature. Recanati himself emphasizes in his most recent book that, even if what is said is logically prior to the working out of implicatures, it is not temporally prior in the sense that recovery of what is said takes place before any implicatures can be computed (Recanati 2004,47 ), but he still finds reasons to maintain his differentiation between primary and secondary pragmatic processes.

Carston (1988) is a very influential paper that deals with, and defends, the functional autonomy of explicatures and implicatures in the pragmatic processing of utterances. Let us look at one of her examples Carston $(1988,155)$.

(1) A How is Jane feeling after her first year at university?

B She didn't get enough units and can't continue. 
Carston notes that there are certain words in B's answer that are in need of disambiguation. This is true of the verb get and the noun unit, she says - though today she would presumably prefer to say that both get and unit are conceptually underspecified words that are subject to ad hoc development in context, and that no lexical ambiguity is involved here. No one would deny that on the implicit side of the pragmatic analysis of B's answer is the derived assumption that Jane regrets the situation she finds herself in, but that implicature is based on an interpretation of the phrase can't continue as 'cannot continue with her university studies' and the phrase enough units as 'enough university course units to qualify for admission to second year study', information which is not encoded but which is represented in the hearer's LoT (Language of Thought) as a result of pragmatic enrichment of the encoded logical form. Also, the predicate get is regularly in need of lexical narrowing, a pragmatic process that will be sensitive to the semantics of especially the direct object argument of this verb and has nothing to do with implicature derivation.

What general criteria do we possess, which enable us to decide whether the pragmatic developments of the grammatical phrases enough units and can't continue in (1) belong to the proposition expressed, the output of mental processes of 'free enrichment' like narrowing or loosening of the encoded meaning, or are instead conceptual constituents of an implicature? Back in 1988 Carston suggested a criterion of functional independence of the explicature of an utterance and any implicatures of the same utterance as part of the answer to this question: the Functional Independence Principle. Adopting this principle means that any alleged implicature that is seen to subsume all contextual effects that could be derived from the proposition expressed by an utterance cannot maintain its status as implicature; rather it should be redefined as the explicature, a hybrid mental representation made up of conceptual structure provided via the encoded logical form of the utterance on the one hand and context-sensitive inferences on the other. ${ }^{1}$ However, Carston hastens to add that "while it is instructive to consider such criteria, they might well be seen as rather superficial, descriptive principles, if not ad hoc", because, she says, "they follow from a single principle directing utterance interpretation, the principle of relevance, which is itself embedded in a general theory of human cognition and communication, the relevance theory of

[1] Today there are certain indications (e.g. in Hall 2008) that the 'hybrid representation' hypothesis is less solidly established in relevance-theoretic circles than it was just a few years ago. Is decoding of the linguistically encoded meaning of a sentence a mental process that operates directly on a logical form provided by the language module itself, or does all pragmatic enrichment take place in LoT because the so-called logical form is itself a conceptual representation in LoT, distinct from any natural language representation of decoded semantic structure (which is probably non-existent)? If the latter position is adopted, then our recognition and understanding of the explicature of an utterance will not depend on the output of the grammar on the one hand and inference on the other hand, because even 'linguistic decoding' will then be defined as a non-linguistic thought process and as such it is hardly a process independent of contextual input. 
Sperber \& Wilson (1986)" (Carston 1988, 156). This toning down of the significance of the Functional Independence Principle was later seen to be followed up by a stronger concession on her part (Carston 2002, 191),

However, it is not clear to me that 'functional independence' is worth any kind of vigorous defence; it was in fact intended as only a useful heuristic and should probably never have been elevated by the label 'principle' at all. I was (and am still) of the view that the communicative principle of relevance itself or, more particularly, the comprehension strategy ${ }^{2}$ that follows from it, effects a sorting of pragmatic inferences into contributions to the proposition expressed (explicature) and implicatures, and so subsumes whatever correct predictions 'functional independence' might make. (Carston 2002, 191)

As an example of what she means by saying that the explicature of a given utterance must play a communicative role that is independent of the role of any implicature derived via pragmatic processing, and vice versa, Carston considered the exchange between A and B in (2) in her 1988 article.

(2) A Have you read Susan's book?

B I don't read autobiographies.

implicated premise: Susan's book is an autobiography.

implicated conclusion: B has not read Susan's book.

(Carston 1988, 157)

In (2) the truth conditions pertaining to the implicatures 'Susan's book is an autobiography' and 'B has not read Susan's book' are independent of the truth conditions of the explicature ' $\mathrm{B}$ does not read autobiographies'. There is no overlap in content between the explicature and the implicatures, which function independently of the explicature as premise and conclusion in a process of nondemonstrative inference (cf. Sperber and Wilson 1986).

Suppose the functional independence criterion were found not to hold water, so that even its usefulness as a heuristic might be questioned. Would a disclosure of the empirical shakiness of the criterion have consequences for the relevancetheoretic view of the semantics/pragmatics distinction and the distinction between explicit and implicit communication? I am going to argue that Carston's Functional Independence Principle should not be accorded any role in a cognitively based theory of utterance interpretation like relevance theory. There is rather strong empirical evidence that this principle is not tenable; fortunately, the viability of relevance theory does not in any way hinge on it.

[2] The relevance-theoretic comprehension strategy enjoins addressees to construct interpretation in order of accessibility and to stop when their expectation of relevance is satisfied. 


\section{[2] AN EXPLICATURE CAN ENTAIL AN IMPLICATURE}

Carston $(2002,137-41,189-91)$ has observed that there can be no incompatibility between the fact that an explicated proposition $p$ entails a proposition $q$ and the assumption that the entailed proposition $q$ is an implicature derived through the hearer's processing of the explicature $p$ in a specific context. The existence of situations where an implicature of an utterance is an entailment of the explicature of the same utterance would appear to be a counterexample to the Functional Independence Principle. If the implicature is entailed by the explicature of the utterance, the two communicated assumptions cannot both be autonomous, they are not independent of one another.

Carston did not draw the conclusion that the existence of implicatures that are entailed by the proposition expressed - as in (4) B below - is bad news for the relevance-theoretic view of the contrast between explicated and implicated propositions. In contrast to (3), the corresponding answer in (4), adapted from Carston $(2002,190)$, implicates that B did buy vegetables, because B bought a squash and an eggplant. In (4) the implicated conclusion is entailed by B's explicated premise.

(3) A Did you buy any vegetables?

B I bought some apples and pears.

implicature: B did not buy any vegetables

(4) A Did you buy any vegetables?

B I bought a squash and an eggplant.

implicature: B bought some vegetables

Carston concludes, "In my view, the concept of 'entailment' and the concept of 'implicature' belong to different explanatory levels or different sorts of theory, the one a static semantic theory, the other a cognitive processing pragmatic theory" (Carston 2002, 141). ${ }^{3}$

\section{[3] AN IMPLiCATURE CAN ENTAIL AN EXPLiCATURE}

I am now going to show that we also have to allow for the existence of situations in which an implicature entails the explicature of an utterance. Carston's independence principle was meant to give pragmatists a criterion that would enable them to tell explicatures and implicatures apart in cases of doubt. Her argument was that, if the meaning of the explicature is fully included in the meaning of

[3] Burton-Roberts (2005) strongly disagrees with Carston that an entailment of the explicature of an utterance can be implicated. When you explicate a proposition $p$, his argument goes, then you explicate the truth-conditional content of $p$, which includes all entailments of $p$. Hence if an entailment of $p$ is implicated, then $p$ is implicated. To deny this, he says, would be to construe 'entailment' in a novel, idiosyncratic and unprecedented way. 
an implicature derived on the basis of the explicature and a set of contextual assumptions, then the explicature will be redundant, as no contextual effect can be derived from the explicature which is not at the same time derivable from the entailing implicature. The thought represented by the explicature is duplicated in a truth-conditionally stronger implicature.

The Functional Independence Principle supports Carston's own proposal that all Gricean generalized conversational implicatures be eliminated, including the reasoning from ' $p$ and $q$ ' to ' $p$ and then $q$ ' ('conjunction buttressing') and the reasoning from 'if $p$, then $q$ ' to 'if and only if $p$, then $q$ ' ('conditional perfection'), where the stronger readings are said to be due to generalized conversational implicatures, Levinson's GCI's (Levinson 2000), which are triggered by the presence of particular linguistic elements. For relevance theorists all legitimate implicatures are of the particularized sort (PCI's), the outcome of 'one-off inferences'. The claim that GCI's should be dispensed with is based on the fact that relevance theorists embrace a view of explicit communication as much more contextdependent and inference-driven than what had been assumed by Grice and the neo-Griceans. An explicature is defined as an ostensively communicated assumption which is inferentially developed from a truth-conditionally incomplete encoded logical form (Sperber and Wilson 1986; Carston 2002). All standard examples of GCI, which a neo-Gricean like Levinson (2000) regards as a preferred or normal interpretation based on default inference, are redefined as explicatures in the framework of relevance theory. Like any other explicature, the ones that Grice defined as GCI's are conceived by relevance theorists as the result of a union of a grammar-dependent logical form and context-based inference supported by the communicative principle of relevance. ${ }^{4,5}$

The reasoning that underpinned Grice's argument that a coordinating connective like English and gives rise to what he called a generalized conversational implicature was prompted by his intention to prove that natural language operators like conjunction and disjunction connectives and conditional connectives work exactly like the corresponding operators of propositional logic. The fact that we often understand a speaker's use of the connective and as if she had actually said and then is due to factors that are extraneous to whatever information the language code can give us. Such inferences about what the communicator means by what she says were claimed by Grice to be due to principles of conversation, his Co-operative Principle and his four categories of conversational maxims (Grice

[4] The communicative principle of relevance says that, "Every act of ostensive communication communicates a presumption of its own optimal relevance" (Sperber and Wilson 1995, 260)

[5] Although it will be no major point in the present paper, I confess that I am no longer willing to take for granted the notion of a grammatically determined semantic representation which is a subpropositional conceptual structure. It is conceivable that logical properties are not found in natural-language representations at all and that only information represented in LoT has logical properties. See Burton-Roberts (2007), Amfo et al. (2007), Fretheim (2008) - as well as footnote 1 of this paper. 
1975, 1989). A given English conjunction of clauses or verb phrases conforming to the general formula ' $p$ and $q$ ' may implicate ' $p$ and then $q$ ' in one context, ' $p$ and therefore $q$ ' in a different context, etc. More strongly than any other publication, Carston's 1988 paper offered a very clearly expressed alternative to the standard implicature analysis of the temporal and causal implications of the use of and-conjunction.

If it turns out that we have to allow for the existence of situations where an implicature entails the proposition expressed, the usefulness of the Functional Independence Principle as a heuristic will be seriously diminished. On the other hand, empirical evidence that might cause the demise of the Functional Independence Principle has been scarce. Having addressed an argument that Recanati (1989) presented against her Functional Independence Principle, Carston (2002, 191) retorted, "A more compelling counterexample to the principle would involve a communicated assumption which (...) is clearly an implicature, but which is an implicated premise (rather than an implicated conclusion) and entails what is said; I have not come across such a case." (her emphasis). She did not tell the reader why she feels an implicated premise that entails what is said would be more damaging to the RT view of the saying-implicating distinction than an implicated conclusion that entails what is said.

I have chosen not to cite Recanati's fairly complicated counterexample in the present paper. However, Burton-Roberts (2005), which is a review of Carston (2002), presents data that may be a problem for Carston's proposal about the functional autonomy of explicatures and implicatures. The kind of example on which his argument rests is given in (5). ${ }^{6}$

(5) A There's no milk.

B The milkman's ill.

B's answer implicates that there is no milk because the milkman is ill. In other words, what B implicates subsumes what B says, or explicates, which is no more than that the milkman is ill. The implicature that there is no milk because the milkman is ill entails the explicature of B's utterance in (5). On Carston's account the thought 'There is no milk in the house because the milkman is ill' should preferably be explicated, not implicated, by B's utterance of The milkman's ill. However, the explicated assumption that he is ill is functionally independent of the explicature of A's utterance and independent of any inferred causal relation between B's explicature and A's explicature. I do not think anything would stop a relevance theorist from saying that the logical form of B's sentence can be developed into a more complex explicature that may be paraphrased as 'There is no

[6] I am grateful to Noel Burton-Roberts for pointing footnote 8 of his review article out to me (Burton-Roberts 2005, 397). 
milk in the house because the milkman is ill', and so it seems to me that BurtonRoberts' milkman example might lead to a paradox for relevance theory, although Burton-Roberts himself did not intend his counterargument to the Functional Independence Principle to be interpreted that way. He insists (p.c.) that the causal relation between the premise $p$ and the conclusion $q$ in (5) cannot be explicated even for Carston. One thing is clear: the assumption that there is no milk because the milkman is ill cannot be both implicated and explicated by B's utterance.

An anonymous reviewer offered me the interesting alternative of ( $\left.5^{\prime}\right)$ to the data in (5). In the talk exchange of (5') there are three participants: A, B, and C.

(5') A There's no milk.

B The milkman's ill.

C No, it's because his company's on strike.

What is C objecting to? The explicature of B's utterance with a built-in causal relation, or an implicature which communicates the causal relation between A's explicature concerning the lack of milk and B's explicature concerning the milkman's health condition? We do not have reliable tests that enable us to answer this question in an adequate way, and from a communicative point of view the decision does not really matter, because the relevance of C's utterance certainly does not depend on our professional view of how we should draw the line between free enrichment and implicature. It would appear that $C$, who is rejecting Bs premise $p$ and offering a new one, is treating the causal relation between $p$ and $q$ as part of the explicit content of B's utterance. However, there is no rule against performing an act of denial that addresses a thought which is implicated by the interlocutor's previous utterance rather than explicated. The speaker's communicated belief about the interlocutor's belief that $q$ was caused by $p$ remains the same on either analysis.

I am now going to present what I judge to be a better example of an implicature that entails the explicature of the utterance. Consider the minimally different question-answer pairs in (6) and (7). ${ }^{7}$

(6) A What happened when that bug flew into your mouth?

B I swallowed it.

(7) A What happened when that bug flew into your mouth?

B I swallowed.

The linguistic intuition of native speakers of English is such that they understand the proposition expressed by the utterance of (7) B differently than the proposition expressed by the utterance of (6) B. The version in (6) with an overt direct

[7] Anne Bezuidenhout's paper 'The Semantics/Pragmatics boundary' (2005) aroused my interest in the verb swallow and its lexical correspondents in other languages. 
object argument is a direct way of saying that B swallowed the bug; the version in (7) with no complement after the verb is an indirect way of conveying that information. Non-native speakers of English generally feel the same about this pair, because they draw on their native language competence and their own language shows exactly the same lexical difference between an intransitive verb and a phonologically identical transitive verb that may both be glossed as 'swallow'.

I am going to argue that there is no process of enrichment that takes you from the encoded logical form of B's answer in (7) to an explicature that equals the explicature communicated by B's answer in (6). We understand the answer in (7) to convey an explicit premise that opens for the implicated conclusion that the bug was passed down into B's stomach when B swallowed. The addressee of (7) $B$ is aware of what is said and is capable of working out the inferential connection between what is said ('I swallowed') and what is implicated by what is said ('My swallowing caused me to swallow the bug'). This is a 'post-propositional', 'secondary' pragmatic process in Recanati's sense. It meets his availability condition, unlike the 'primary' pragmatic processes of mandatory saturation like the resolution of the reference of the pronoun it in (6).

Bach (1994) introduced the notion of 'impliciture', standing for what is implicit in what is said, as what he considered to be a viable alternative to the relevance-theoretic 'explicature'. ${ }^{8}$ He makes a terminological distinction between 'conceptual incompleteness' and 'semantic incompleteness'. Conceptual completion, or what Bach calls 'expansion', is sometimes required to arrive at the 'impliciture' of an utterance. This is for him a case of free enrichment. Semantic completion on the other hand is when the context supplies an argument for an implicit argument role. In such cases Bach's 'impliciture' would be arrived at via saturation, or what Bach calls 'completion'. When someone says I've finished, there may be an implicit argument role there for the activity that was finished, and context will help in the recovery of the event which occupies the implicit argument role. The same is presumably true of the null-complement of the verb notice in (8).

(8) A William was very silent today.

B Yes, I noticed.

A process of mandatory saturation is required for the hearer's mental representation of what B noticed. Though there is no overt complement after the verb notice, this is nevertheless a transitive verb whose argument structure includes an argument that refers to the object of the act of noticing. The verb finish is similarly conceptually transitive even when it has no overt object argument.

[8] What I've written in this paragraph is in large part due to personal communication with Anne Bezuidenhout. 
Could the verb swallow be analyzed in the same way as finish and notice? Does the inferential processing of B's answer in (7) involve mandatory saturation, Bach's 'completion'? Hardly, because the intransitive verb swallow encodes a different concept than its transitive counterpart. There is no hidden or overt argument referring to that which is swallowed when swallow is used as an intransitive verb. Nor is it possible to let a sentence with the intransitive verb swallow undergo 'free enrichment' that results in an explicature that represents an unmentioned affected object. If you wish to explicate the information that a particular solid object or liquid stuff was swallowed, you have to fill in the direct object slot, even if the linguistic filler is just a pronoun that represents a contextually very salient discourse entity, as in (6).

In order to convince you that intransitive and transitive uses of swallow are semantically distinct, I suggest we consider the pair of (9)-(10).

(9) Mark swallowed twice.

\#Mark swallowed it/something twice.

An utterance of (9) causes us to infer that Mark swallowed without swallowing anything. There may have been nothing in Mark's mouth that could possibly be swallowed. (9) is meaningful but (10) will not normally be, because when something has been swallowed it is hard to see how it could be swallowed once more.

The American Heritage Dictionary of the English Language lists two basic, non-figurative meanings of the verb swallow, one of which corresponds to its meaning when it is a transitive verb and the other one to its meaning when it is used intransitively. According to this dictionary, the transitive verb swallow means "to cause (food, for example) to pass from the mouth via the throat and the esophagus into the stomach by muscular action", and "ingest" is suggested as another verb with that meaning. Under the same dictionary entry we also find an intransitive use of the verb swallow, whose meaning is defined as "to perform the act of swallowing". The Oxford Paperback Dictionary \& Thesaurus similarly tells us that the verb swallow has two meanings, one for its transitive and one for its intransitive use. The former is "to cause (food, drink, etc.) to pass down the throat", and the latter "to move the throat muscles as if doing this, especially through fear", where demonstrative this refers to the action denoted by the transitive verb. Finally, Shorter Oxford Dictionary distinguishes between the lexical meaning of the transitive verb swallow, which is said to be "to take into the stomach through the throat and gullet, as food or drink", and the intransitive verb, whose meaning is entered as "to perform the act of deglutition, as in an effort to suppress emotion" ("deglutition" is a scientific word for "swallowing"). The muscular action involves shutting of the epiglottis so that the entrance to the trachea is shut off, and the intransitive verb swallow encodes no more information than the phrase perform an 
act of swallowing does. In contrast, the transitive verb swallow encodes the complex deglutition concept, which necessarily includes the physical mechanism encoded by intransitive swallow as an instrument.

Suppose we change A's utterance in the above pair (6)-(7) slightly and replace past tense swallowed by the present perfect tense form have swallowed.

(11) A So what happened to the bug that flew into your mouth?

B I've swallowed it.

(12) A So what happened to the bug that flew into your mouth?

B \#I've swallowed.

If we accept the hypothesis that it is possible to let an utterance of the sentence I've swallowed undergo free enrichment so that the contextually derived explicature will be something like 'I have swallowed the bug that flew into my mouth', then we have no explanation for our feeling that B's utterance I've swallowed is incoherent in the context provided by A's question in (12), a question about the fate of the poor bug. To the extent that (12) B makes us think of a deglutition process of swallowing the bug, it does so in spite of the syntactic form of the sentence used by B, which is not an acceptable way of communicating what was said in (11). While the explicature of B's answer in (7) above leads us straightforwardly to the truth-conditionally more constrained implicated conclusion that B swallowed the bug, B's answer in (12) tells us that B performed an act of swallowing and leaves us with a feeling that the answer is either not relevant with regard to the question asked by A, or else produced by someone whose English proficiency is rather poor, ${ }^{9}$ which may cause the native English interlocutor A to condone the fact that there is a missing overt object argument in B's utterance and interpret the utterance I've swallowed as if B had actually said I've swallowed it.

Observe that my example with the verb swallow involves no potential paradox similar to what we experience with Burton-Robert's example. It is not so that the thought 'B swallowed the bug' arising from (7) B is implicated according to one criterion and explicated according to a different criterion. My argument is that there is no reason to even consider an explicature analysis to be a possible candidate in (7), because native speakers of English do understand the proposition expressed by B in (7) to be ostensively distinct from the proposition expressed by B in (6), and the noted difference in acceptability between (11) B and (12) B corroborates the evidence presented earlier.

Why do I insist that there is a genuine difference between my own example of an implicature that entails the explicature of an utterance and Burton-Roberts'

[9] Sperber and Wilson's 'presumption of optimal relevance' (Sperber and Wilson 1995, 270) includes the following statement: The ostensive stimulus is the most relevant one compatible with the communicator's abilities and preferences (emphasis mine). 
mentioned example of the same phenomenon? Let us repeat his data for convenience.

(5) A There's no milk.

B The milkman's ill.

In Burton-Roberts' illustration rendered in (5), the causal relation between B's proposition (reason) and A's proposition (consequence) is arguably expressed in a direct manner. $B$ could have given the same answer by using the more complex sentence structure 'There's no milk because the milkman's ill', which requires more decoding but less context-dependent inference. What B did instead was to suppress repetition of information that would just be an echo of what A said in (5). $B$ could also have used a demonstrative pronoun to represent the consequence: 'That's because the milkman's ill'. The pragmatic processing of what B says in (5) arguably involves a pragmatic completion process, a relevance-theoretic enrichment of the free sort. At the same time there may also be fairly strong arguments for an analysis of B's utterance as one which gives rise to an implicature that subsumes the explicature.

My example (7), repeated here, is different. B's 'when'-clause in (7'), an echo of A's identical clause, does not change our interpretation. What we see in ( 7 ') is the intransitive verb swallow, grammatically and conceptually, even if the given information expressed in the temporal clause of A's question is echoed in B's answer. The assumption that B swallowed the bug is no more explicated in ( $\left.7^{\prime}\right)$ than in (7).

(7) A What happened when that bug flew into your mouth?

B I swallowed.

(7') A What happened when that bug flew into your mouth?

B I swallowed when that bug flew into my mouth..

I conclude that the assumption that speaker B swallowed the bug is conveyed in a truly indirect way in (7), while the assumption that there is no milk because the milkman is ill is conveyed in a less obviously indirect way in Burton-Roberts' example (5). There was a suppressed proposition in (5) B whose recoverability depended on the content of interlocutor A's utterance, but there is no suppressed proposition in (7) B that is brought into focus by the content of A's preceding utterance. The anonymous reviewer of this paper mentioned that the answer in (7) could be analysed as a sort of euphemism, where B is deliberately not communicating explicitly what happened when the bug flew into his mouth, maybe because the incident was so embarrassing or so unpleasant that he does not feel like talking about it. I agree with the reviewer's judgment that these are possible implicatures that would not necessarily be associated with the utterance of (6) 
$\mathrm{B}$, and this corroborates my view that the utterances of (6) B and (7) B differ in their overall relevance, even though both utterances communicate the assumption that B swallowed and the assumption that B swallowed the bug.

Neither Carston nor any other relevance theorist has thus far offered us necessary and sufficient conditions that enable us to decide where free enrichment at the explicit level of communication stops and implicature takes over. ${ }^{10}$ A relevance theorist could, if so inclined, argue that B's answer in (5) directly explicates the information that there is no milk because the milkman is ill, in which case (5) would be no threat to the Functional Independence Principle. In contrast, the explicature of B's answer I swallowed in the exchange between A and B in (7) can be paraphrased as 'I performed an act of swallowing', and this is a self-contained communicated thought. B did not mean to swallow but it unfortunately happened, and the (implicated) consequence was the bug's being passed down into B's stomach. By saying I swallowed, B did not explicate either 'I swallowed, so I swallowed the bug that was in my mouth' or the truncated version 'I swallowed the bug that was in my mouth'.

\section{[4] CONCLUSION}

My example involving the verb swallow, and the argument that rests on it, shows that there are situations where an implicature of an utterance entails its explicature, but the fact that an explicature can be entailed by an implicature is not a problem for relevance theory, it affects none of its fundamentals. We still have what Carston $(2002,191)$ refers to as embedding tests, of which the most famous one is Recanati's Scope Principle (Recanati 1989). The Scope Principle says that a pragmatically determined aspect of meaning is part of what is said (thus no implicature) if it falls within the scope of logical operators such as negation or a conditional connective. When applied to conjunction data, this test reveals that the strengthened interpretations involving a temporal sequence or a causal relation between the conjuncts come out as explicatures, or what is said in Recanati's sense.

Even if the explicature of B's utterance in my example (7) is entailed by an implicature communicated by means of that utterance, this fact does not necessarily mean that the explicature is made redundant (because it would yield no contextual effects that are independent of the contextual effects of the entailing implicature). It cannot be literally true that speaker B's utterance of the sentence I swallowed in (7) yields no contextual effect apart from what is attributable to the implicature 'B swallowed the bug that had flown into B's open mouth'. The expli-

[10] Lack of clarification concerning the limits of processes of free enrichment relative to derivation of implicatures may at the end of the day turn out to be a nagging problem for relevance theory. For some interesting thoughts on how the concept of free enrichment must be constrained, see Nishiyama and Mineshima (2007, 2008). See also Hall (2008). 
cature of B's utterance in (7) possibly makes it easier for the hearer to infer that $B$ swallowed ${ }_{1}$ (let me use subscript 1 for the concept encoded by the intransitive verb swallow) by mistake. He should not have swallowed ${ }_{1}$ at that particular time, because by so doing he could not help swallowing 2 (let me use subscript 2 for the concept encoded by the transitive verb swallow) the bug that had flown into his mouth. (6) B - I swallowed it - is compatible with the assumption that B deliberately swallowed 2 the bug. (7) B - I swallowed - strongly suggests that it happened by accident.

Still, this possible pragmatic difference between (6) B and (7) B is not the main reason why I think the kind of data that I have focused on in the present paper should not worry relevance theorists, even though I do think the mentioned semantic properties of transitive and intransitive swallow show that the Functional Independence Principle should be abandoned. In my view, the relevance of B's utterance in (7) is not dependent on the inferred assumption that the swallowing happened by mistake. There is absolutely no reason to doubt that the explicature of the utterance of (7) B is sufficiently relevant in spite of the fact that it is entailed by the strongly communicated implicature that B swallowed the bug. After all, Carston herself has insisted that the concept of 'implicature' belongs to a cognitive theory of on-line processing of information, while the concept of 'entailment' belongs to a static theory of semantics. One major contextual effect of B's answer in (7) is the explicated information that B swallowed ${ }_{1}$, and this gives the hearer the opportunity to activate one or more weakly communicated implicatures that would be less accessible if the transitive verb swallow (swallow $)_{2}$ had been used.

I would go as far as to claim, presumably against the opinion of Carston and other relevance theorists, that for the addressee $A$ the mental representation of the communicated assumption that B swallowed (when the bug had flown into his mouth) is temporally prior to A's mental representation of the implicated conclusion that $B$ swallowed ${ }_{2}$ the bug when he swallowed ${ }_{1}$. In my view the temporal sequence is no less crucial here than in an imagined situation where B actually says the following, in a discourse where there has been no prior mention of a bug: I swallowed - so I swallowed a bug, with a temporal break, for rhetorical effect, between the two clauses.

\section{AC KNOWLEDGEMENT}

I am indebted to Anne Bezuidenhout and Noel Burton-Roberts for very useful discussions, and to an anonymous reviewer for taking such an interest in my topic and offering me some acute judgments and some further arguments. Any weaknesses are my responsibility alone. 


\section{REFERENCES}

Amfo, N. A. A., Fretheim, T., Haugereid, L. and Nakijoba, S. 2007. The scope of negation: How much depends on pragmatic inference? ISK Working Papers 4, $17-42$.

Bach, K. 1994. Conversational impliciture. Mind \& Language 9, 124-162.

Bezuidenhout, A. 2005. The Semantics/Pragmatics boundary. In K. Brown (ed.), 2nd edition of The Encyclopedia of Language and Linguistics, Elsevier Publishers.

Burton-Roberts, N. 2005. Robyn Carston on semantics, pragmatics and 'encoding'. Journal of Linguistics 41, 389-408.

Burton-Roberts, N. 2007. Varieties of semantics and encoding: negation, narrowing/loosening and numericals. In N Burton-Roberts (ed.), Pragmatics, pages 90-114, Basingstoke: Palgrave Macmillan.

Carston, R. 1988. Implicature, explicature, and truth-theoretic semantics. In R. M. Kempson (ed.), Mental Representations: The Interface between Language and Reality, pages 155-182, Cambridge: Cambridge University Press.

Carston, R. 2002. Thoughts and Utterance: The Pragmatics of Explicit Communication. Oxford: Blackwell Publishing.

Fretheim, T. 2008. Some critical remarks on the explicature-implicature distinction in relevance theory. Paper presented at the 23rd Scandinavian Conference of Linguistics, Uppsala.

Grice, H. P. 1975. Logic and conversation. In P. Cole and J. L. Morgan (eds.), Syntax and Semantics, volume 3, pages 41-58, New York: Academic Press.

Grice, H. P. 1989. Studies in the Way of Words. Cambridge MA: Harvard University Press.

Hall, A. 2008. Free enrichment or hidden indexicals? Mind \& Language 23, 426-456.

Levinson, S. C. 2000. Presumptive Meanings: The Theory of Generalized Conversational Implicature. Cambridge MA: The MIT Press.

Nishiyama, Y. and Mineshima, K. 2007. Property expressions and the semanticspragmatics interface. In P. Cap and J Nijakowska (eds.), Current Trends in Pragmatics, pages 131-151, Cambridge: Cambridge Scholars Publishing.

Nishiyama, Y. and Mineshima, K. 2008. Free enrichment and the over-generation problem. Paper presented at The conference Interpreting for Relevance: Discourse and Translation, Kazimierz Dolny, Poland. 
Recanati, F. 1989. The pragmatics of what is said. Mind \& Language 4, 295-329.

Recanati, F. 1993. Direct Reference: From Language to Thought. Oxford: Blackwell Publishing.

Recanati, F. 2004. Literal Meaning. Cambridge: Cambridge University Press.

Sperber, D. and Wilson, D. 1986. Relevance: Communication and Cognition. Oxford: Blackwell Publishing.

Sperber, D. and Wilson, D. 1995. Relevance: Communication and Cognition. 2nd edition, with a Postface. Oxford: Blackwell Publishing.

\author{
AUTHOR CONTACT INFORMATION \\ Thorstein Fretheim \\ Norwegian University of Science and Technology \\ Dept. of Language and Communication Studies \\ N-7491 Trondheim \\ Norway \\ thorstein.fretheim@hf.ntnu.no
}

